Original article

Section: Food Quality and Functionality

\title{
Effect of Glucosamine and Ascorbic Acid Addition on Beef Burger Textural and Sensory Attributes
}

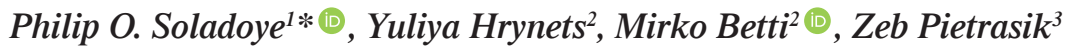 \\ ${ }^{1}$ Agriculture and Agri-Food Canada, Lacombe Research and Development Centre, Lacombe, Alberta, T4L IWI, Canada \\ ${ }^{2}$ Department of Agricultural, Food and Nutritional Science, \\ University of Alberta 410 Agriculture/Forestry Centre, Edmonton Alberta, T6G 2P5, Canada \\ ${ }^{3}$ Food Processing Development Centre, Food and Bio Processing Branch, \\ Alberta Agriculture and Forestry, Government of Alberta, Leduc, Alberta, T9E 7C5, Canada
}

Key words: glucosamine, ascorbic acid, beef burger, consumer acceptability, quality attributes

Aside from the possible health benefit of dietary consumption of glucosamine $(\mathrm{GlcN})$, studies have also reported its flavour enhancing properties in varying food products. However, the impact of its inclusion on other quality attributes of meat products has been under-assessed. The present study examined the effect of the addition of ascorbic acid $(0.1 \%)$ and varying levels of $\mathrm{GlcN}(0.75,1.5$ and $3.0 \%)$ on colour stability, textural as well as sensory attributes of beef burger. Except for $L^{*}$ (lightness) value, significant interaction $(p<0.01)$ between storage time and added ingredient was observed for all colour parameters ( $a^{*}$; redness, $b^{*}$; yellowness, chroma, and hue angle) in beef burger. Generally, although ascorbic acid preserved the colour attributes of beef burgers during storage, addition of GlcN resulted in the deterioration of these colour parameters. Whereas the present result did not confirm any flavour enhancing attributes of GlcN compared to control, GlcN improved beef burger's yield and reduced product cook loss. However, level of GlcN above $1.5 \%$ resulted in significant flavour and textural deterioration $(p<0.05)$, leading to decline in consumer acceptability of beef burger. This study showed that a moderate level of glucosamine could be used in meat products as a functional ingredient with some additional technological benefits and limited impact on sensory attributes. Ascorbic acid adequately protected the colour of beef burger during refrigerated storage.

\section{INTRODUCTION}

In recent years, epidemiological studies are associating red and processed meat with several human disease conditions including cardiovascular disease, colorectal/colon cancer, diabetes and thrombosis, among others [Chan et al., 2011; Micha et al., 2010]. The attributes of red and processed meat largely implicated in this disease associative effect may include their saturated fatty acid content, sodium salt content as well as the severity of their processing. Considering these recent trends, consumers tend to scrutinize their meat consumption; demanding for clean label, minimally processed and reduced salt meat products. One of many possible strategies for sodium salt reduction in meat products is the incorporation of flavour enhancer in place of salt in meat product formulation [Hong et al., 2016].

Glucosamine (GlcN, 2-amino-2-deoxy-D-glucose), also referred to as chitosamine, is a naturally occurring amino sugar found around the bone joints and plays a vital function in cartilage building. GlcN is also made available as dietary supplement through the hydrolysis and deacetylation of chitin mainly derived from the exoskeleton of marine crustaceans and shellfishes [Hong \& Betti, 2016]. GlcN supplement has been used in the prevention and treatment of osteoarthritis symptoms [Bruyere \& Reginster, 2007; Hrynets et al., 2016; McAlindon et al., 2000]. Although not without debates, other health claims reported for GlcN include improvement and ease of inflammatory bowel diseases (3-6 g of $N$-acetyl glucosamine administered orally or rectally to children daily for unspecified period) [Salvatore et al., 2000]; bone healing and pain alleviation $(230 \mathrm{mg} / \mathrm{kg}$ glucosamine-sulfate daily intraperitoneal for 4 weeks to Wistar rats) [Uğraş et al., 2013]; as well as treatment of immunological diseases $(10 \mu \mathrm{g} / \mathrm{mL}$ of 5-40 mM D-GlcN or deoxyfructosazines on Jurkat cells) [Zhu et al., 2007]. Aside from these potential health benefits associated with GlcN, this amino sugar could also find applications in the food industry since several studies have reported its antimicrobial [Hrynets et al., 2016], antioxidant [Gottardi et al., 2014; Hong \& Betti, 2016; Xing et al., 2006] and flavour/ taste enhancing potentials [Fu et al., 2020], especially when incubated at moderate temperatures (between 25 and $50^{\circ} \mathrm{C}$ ). Jia et al. [2014] have proposed a one-pot dehydration process

\footnotetext{
* Corresponding Author: 
for the conversion of GlcN into fructosazine and deoxyfructosazine which can be used as a flavoring agent in the food industry. GlcN can also be used to modify proteins with the aim of enhancing their functionalities [Hrynets et al., 2013]. Other studies have used GlcN to enrich beverages and milk with the aim of creating functional products [Kralovec \& Barrow, 2007; Uzzan et al., 2007].

The flavour enhancing attributes of GlcN can be largely attributed to its unique chemical structure which makes it unstable [Hong \& Betti, 2016] and prone for self-condensation to form non-volatile hydroxyalkyl pyrazines including, fructosazine [2,5-bis(D-arabino-tetrahydroxybutyl)pyrazine] and deoxyfructosazine [2-(D-arabino-tetrahydroxybutyl)-5-(D-erythro-2,3,4-trihydroxybutyl)pyrazine], which have been identified as flavour compounds in some selected foods (including roasted soy sauce, nuts, and caramel) and are recognized to be the precursors of the aromatic volatile pyrazines [Hrynets et al., 2016]. Additionally, Maillard reaction compounds have been reported to possess some taste enhancing potentials [Hong, 2016]. Given that GlcN is capable of triggering a fast Maillard reaction with peptides or proteins at moderate temperature especially between 25 and $50^{\circ} \mathrm{C}$, further makes this compound very attractive as flavour enhancer in an array of food applications [Dhungel et al., 2018]. In fact, GlcN can also undergo degradative reactions at $37^{\circ} \mathrm{C}$ forming reactive $\alpha$-dicarbonyls ( $\alpha$-DCs) including glucosone, 3-deoxyglucosone, methylgyoxal, glyoxal and diacetyl which are important precursors of some desirable flavours [Hong, 2016; Hrynets et al., 2016].

Ascorbic acid (ASC) is a proven antioxidant widely used in meat processing although it can act either as pro- or antioxidant depending on the concentration, the presence of metal ion as well as the presence of other components [Schaefer et al., 1995]. Several studies have reported the effectiveness of ascorbic acid in maintaining the stability of beef colour and lipid [Ahn \& Nam, 2004; Sen et al., 2014]. Given that the colour of meat is considered the most important quality characteristics influencing consumer appeal and purchasing decision, several intervention strategies to prevent meat discoloration and oxidation have been proposed. However, the recent concerns about safety and consumers' heightened interest in natural antioxidant has resulted in more researchers exploring ascorbic acid as replacement for conventional antioxidants. This antioxidant enhances quality attributes of meat, prevents discoloration, and extends the shelf life significantly.
Following these aforementioned studies, aside from its acclaimed health benefits, it seems promising that GlcN can significantly enhance the flavour of meat products. However, the consequences of their inclusion on other important meat products' quality attributes remain unknown. The present study hence intends to evaluate the impact of GlcN and ASC addition on sensory and quality attributes of beef burger. Specific flavour effects of GlcN and ASC on beef burger will be examined. Other possible effects of the inclusion levels of these compounds on meat technological/processing attributes will also be considered.

\section{MATERIALS AND METHODS}

\section{Burgers manufacturing}

Fresh beef trimmings (shoulder clod and beef plates) were purchased from local processors. Glucosamine in the form of D-glucosamine hydrochloride and ascorbic acid were purchased from Pure Bulk Inc. (Roseburg, OR, United States). Commercially available toasted wheat crumb (Breader B34216 White \#50, Newly Weds, Edmonton, AB, Canada) was produced and supplied by Newly Weds Foods (Edmonton, AB, Canada).

Five different burger formulations were processed on the same day at the Food Processing Development Centre in Leduc, Alberta, Canada (Table 1). Before processing, beef trimmings were separately ground via a $4 \mathrm{~mm}$ plate (Model AW114, K \& G Wetter, Mississauga, ON, Canada). Samples were withdrawn from each batch of the ground beef and proximate composition analysis was conducted with the aid of Foss FoodScan analyzer (FoodScan Lab, Type 78800 , FOSS, Hillerød, Denmark) according to the method of Anderson [2007]. Pre-determined quantities of ground beef, wheat crumb, spices (i.e. $0.8 \mathrm{~g} / 100 \mathrm{~g}$ salt, $0.15 \mathrm{~g} / 100 \mathrm{~g}$ onion powder, $0.1 \mathrm{~g} / 100 \mathrm{~g}$ black pepper), water $(12 \mathrm{~g} / 100 \mathrm{~g})$, and depending on specific treatment, ASC or GlcN were combined and mixed slowly in a mixer (A-200T, Hobart, Trot, $\mathrm{OH}$, United States) for $45 \mathrm{~s}$ (Table 1). The overall weight of each treatment batch was $8 \mathrm{~kg}$. The mixture was thereafter moulded into $140 \mathrm{~g}(5 \mathrm{oz})$ burger patties using a patty forming machine (Super 54 Patty machine, Hollymatic, Countryside, IL, United States).

Following burger forming, three burger patties from each treatment were packaged individually on Styrofoam ${ }^{\circledR}$ trays

TABLE 1. Burger treatment formulations.

\begin{tabular}{|c|c|c|c|c|c|}
\hline Ingredient (g/100 g) & Control & ASC & $0.75 \% \mathrm{GlcN}$ & $1.5 \% \mathrm{GlcN}$ & $3.0 \% \mathrm{GlcN}$ \\
\hline Ground beef & 81.95 & 81.85 & 81.2 & 80.45 & 78.95 \\
\hline Water & 12 & 12 & 12 & 12 & 12 \\
\hline Seasoning mix & 1.05 & 1.05 & 1.05 & 1.05 & 1.05 \\
\hline Wheat crumb & 5 & 5 & 5 & 5 & 5 \\
\hline Ascorbic acid & - & 0.1 & - & - & - \\
\hline Glucosamine & - & - & 0.75 & 1.5 & 3.0 \\
\hline
\end{tabular}

ASC - ascorbic acid; GlcN - glucosamine. 
enclosed with an $\mathrm{O}_{2}$-permeable film $\left(8,000 \mathrm{~cm}^{3} / \mathrm{m}^{2} / 24 \mathrm{~h}\right.$; Vitafilm, Huntsman Film Products of Canada, Toronto, ON, Canada). The burgers were then placed on double-tier display cabinet (MPM-72, Master-Bilt ${ }^{\circledR}$ Refigeration Solutions, Albany, MS, United States) kept at $4.0 \pm 1^{\circ} \mathrm{C}$ under $24 \mathrm{~h}$ fluorescent lighting with an average light intensity of 1,630 lx $(\mathrm{CRI}=85)$ to monitor instrumental colour change for 5 days. The rest of the burgers were packaged in cardboard boxes separated with plastic liners, frozen and stored at $-20^{\circ} \mathrm{C}$ until subsequent analyses including sensory evaluation.

\section{Evaluation of raw burgers during retail display}

Instrumental colour evaluation of raw patties during retail display

Colour of beef patties was objectively assessed using a hand-held Minolta spectrophotometer (Minolta CM-2500C, Osa$\mathrm{ka}$, Japan) with a $10^{\circ}$ observer angle, $8 \mathrm{~mm}$ aperture and illuminant A, after being calibrated against a white tile prior to readings being taken. Colour observations for lightness $\left(L^{*}\right.$ refers to light reflected), redness ( $a^{*}$ refers to positive red and negative green), and yellowness ( $b^{*}$ refers to positive yellow and negative blue) were taken daily for up to 5 days of simulated retail display under aerobic environments. The reported $L^{*}, a^{*}, b^{*}$ values for each patty were average of six separate readings. Hue angle was also calculated as: $\tan ^{-1}\left(b^{*} / a^{*}\right)$, and the saturation index (chroma) was calculated as: $\left(a^{*} 2+b^{*} 2\right)^{0.5}$.

\section{Evaluation of patties following frozen storage}

\section{Cooking measurements}

Cooking loss for the burger was evaluated following our previously described method [Pietrasik et al., 2020]. Briefly, frozen patties were placed on an electric grill (Garland ED-42B electric broiler, Russell Food Equipment Ltd, Edmonton, AB, Canada) earlier pre-heated to $190^{\circ} \mathrm{C}$. The patties were cooked on the grill while flipping every $3 \mathrm{~min}$, until the internal temperature has reached $71^{\circ} \mathrm{C}$. Following cooking, the cooked burgers were allowed to stand for $5 \mathrm{~min}$ at room temperature and weighed. Cooking loss was estimated based on the weight of the initial frozen patty. Diameter of each burger patty was measured for both raw and cooked patty in two directions at $90^{\circ}$ angle to each other. The dimensional changes were assessed based on the initial diameter of the frozen patty. The diameter and thickness were determined using an electronic calliper. Two diameter readings were taken in two orthogonal directions and four thickness readings were taken $90^{\circ}$ apart from each other from the bottom to the top. Means for each parameter of burger were used to calculate the dimensional shrinkage as:

$$
\underset{\text { Dhrinkage }}{\text { Dimensional }}=\frac{\begin{array}{c}
\text { raw thickness-cooked thickness }+ \\
+ \text { raw diameter-cooked diameter }
\end{array}}{\text { raw thickness }+ \text { raw diameter }} \times 100 \%
$$

\section{pH measurement}

$\mathrm{pH}$ measurements for both raw and cooked products were performed in duplicate with a $\mathrm{pH}$ meter (Hanna Instruments FC240, Canadawide Scientific, Ottawa, ON, Canada). This was done by homogenizing $20 \mathrm{~g}$ sample in $80 \mathrm{~mL}$ deionized water as previously described by Pietrasik et al. [2016a]. $\mathrm{pH}$ was measured on this homogenized sample.

\section{Textural properties}

The textural attributes of beef burgers were evaluated according to texture profile analysis procedure (TPA) [Bourne, 1982] via an Instron texture system (Model 5565, Instron Corporation, Burlington, ON, Canada). Core samples of $22 \mathrm{~mm}$ diameter were excised from the center of each burger and compressed twice to $30 \%$ of their initial height with a $9 \mathrm{~cm}$ flat ended steel plunger at a constant cross-head speed of $60 \mathrm{~mm} / \mathrm{min}$. The TPA parameters; hardness (peak force on first compression $(\mathrm{N})$ ), cohesiveness (ratio of the active work done under the second force-displacement curve to that done under the first compression curve (dimensionless)), springiness (distance the sample recovered after the first compression $(\mathrm{mm})$ ), and chewiness (hardness $\times$ cohesiveness $\times$ springiness $(\mathrm{N} \times \mathrm{mm}))$ were computed [Pietrasik et al., 2016b].

The shear force analysis of cooked beef burgers was carried out for each treatment using an Instron texture system. Burgers were cooked as earlier described and allowed to cool down for about $1 \mathrm{~h}$ at room temperature. Thereafter, a $2.5 \mathrm{~cm}$ wide strip was cut from the middle of each burger patty, making sure that the edges of the burgers were avoided. Samples were sheared with a straight-edge blade fixture at three different sample locations using a crosshead speed of $250 \mathrm{~mm} / \mathrm{min}$. Results of shear force measurements were reported in $\mathrm{N}$.

\section{Consumer acceptability}

Consumer sensory evaluations were performed at the Consumer Product Testing Centre (CPTC), Edmonton, Alberta, Canada. Exactly 108 consumer panelists (54 male and 54 female, age between 18 and 65) were recruited from the CPTC's consumer testing database with the eligibility criteria being that they are regular consumers of grilled beef burgers at least once per month. Consumer panelists were provided monetary compensation for their participation. During cooking, cook chart was drawn to randomize the placement of beef patties on the grill. After the burger reached the required internal temperature $\left(71^{\circ} \mathrm{C}\right)$, patties were cut into $1 / 3$ pieces, wrapped in foil, and placed into a $60^{\circ} \mathrm{C}$ environment chamber to maintain the temperature of the sample until served to panelists. Burgers were served between 1-10 min following cooking. Using a fully randomized block design, consumer panelists received the portioned piece of the patty monadically. The overall acceptability of cooked burger patty as well as the acceptability of appearance, flavour, texture and aftertaste was evaluated using 9-point hedonic scales $(1=$ dislike extremely, 9 = like extremely). A Just-About-Right (JAR) scaling was employed to provide additional understanding into acceptability results. JAR gauges the level of intensity that consumer panelists associate with each specific attribute and can assist in determining areas of opportunity for product improvement. JAR attributes were customized for both flavour and textural attributes. Check-All-That-Apply (CATA) was also used to capture the frequency of consumers' selection of various terms. Terms were generated by the Sensory Evaluation team to assist with targeted insight into certain areas of interest. Presentation of CATA terms was randomized 
for each panelist, with the option provided for panelists to create their own CATA term(s). To avoid carryover of flavour, a $90 \mathrm{~s}$ break was ensured between sample presentation during which panelists cleaned their palate with unsalted crackers and room temperature water.

\section{Statistical analysis}

Three separate replications were conducted for this study. Processing and instrumental data were analysed using the PROC MIXED procedure of SAS (v. 9.1.3, SAS Institute Inc., Cary, NC, United States). The analyses included both the formulation treatment (the fixed) and the processing replication (random) effects. For colour stability data, a simulated retail display day was included in the model. For consumer panel data, XLSTAT (v.XLSTAT 2019.1.3.58109) was used for data analysis. Sensory evaluation day and panelists within each evaluation day were included in the analysis as random factors. Least-squares means were calculated for all main effects or interactions (where applicable) and means separation was done using the Tukey adjustment when the respective F-tests were significant at $p<0.05$. CATA frequency data for texture and flavour were also summarized in a contingency table and subjected to correspondence analysis using chisquare distances and only attributes that came out significant at $p<0.05$ were reported.

\section{RESULTS AND DISCUSSION}

\section{Instrumental colour evaluation}

The colour characteristics of raw meat and meat products largely influence consumer first appeal and overall acceptability of the product. No significant interaction was observed between storage period and treatments for $L^{*}$ value, suggesting that lightness/brightness of burgers was not affected by the tested ingredients over duration of retail display. Although interactions were not significant for $L^{*}$ value, the main effects were significant (Table 2). As aerobic display time increased, there was a gradual decline in $L^{*}$ value, signifying darker meat with storage time. This result is consistent with progressive colour deterioration due to oxidation that could occur in meat or meat products with days in refrigerated storage [Ganhão et al., 2010; Shivas et al., 1984]. Only ASC and $0.75 \%$ GlcN burgers had $L^{*}$ values that were significantly different from each other $(p<0.01)$ while $L^{*}$ values for other treatments were similar. Given the similarities of these values however, the practical significance of this result may be very subtle.

There were significant $(p<0.05)$ interactions between treatments and storage time for $a^{*}, b^{*}$, chroma (saturation index; how vivid or dull the colour is) and hue values (reflected wavelength or colour as seen by the eyes; larger value indicates less red and more metmyoglobin), indicating that color stability was affected by addition of ingredients (Figure 1A-D). Burgers formulated with ASC maintained the highest $a^{*}$ values (i.e., a brightest red colour) for much longer period compared to control and those processed with GlcN. With ASC treatment, the significant reduction in burger red colour was observed only after day 4 of storage, whereas, a more rapid discolouration was observed in the other treatments where a significant colour change occurred as early as on day 1 (in $1.5 \% \mathrm{GlcN}$ ) or day 2 (in control, $0.75 \%$ and $3.0 \% \mathrm{GlcN}$ ) (Figure 1A). Similar pattern was observed with other colour parameters where significant change in $b^{*}$, chroma and hue was only evident on day 4 or 5 in ASC treatment whereas these changes occurred rapidly on day 1 or 2 in control and other GlcN treatments. This result further highlights the reports from other studies which showed the effectiveness of ascorbic acid in preventing the oxidation of oxymyoglobin to metmyoglobin, evading rapid meat discoloration [Ahn \& Nam, 2004; Ismail et al., 2009; Mitsumoto et al., 1991a,b]. Generally, there was a tendency for faster discoloration with increased incorporation level of GlcN leading to decreasing $a^{*}, b^{*}$ and chroma as well as increasing hue value in the burger. This could simply be due to the impact of the colour of GlcN solution itself. Moreover, while GlcN has been reported to show some antioxidant activity [Xing et al., 2006] in some food systems, its ability to also generate reactive oxygen species during incubation [Hrynets et al., 2016] may also suggest some prooxidative factors that could result in oxidative instability of myoglobin as observed in this study and is also worth exploring. It is possible that, depending on the nature of food, the level of inclusion as well as the nature of GlcN in food system, it could serve as either antioxidant or a prooxidant. While this may be speculative to a large extent, the underlining chemistry of this change requires future exploration.

TABLE 2. Lightness $\left(L^{*}\right)$ value of fresh burgers as a function of refrigeration time and glucosamine $(\mathrm{GlcN})$ inclusion level and ascorbic acid (ASC) addition.

\begin{tabular}{|c|c|}
\hline & $L^{*}$ value \\
\hline \multicolumn{2}{|c|}{ Treatment } \\
\hline Control & $53.3^{\mathrm{ab}}$ \\
\hline ASC & $52.3^{\mathrm{b}}$ \\
\hline $0.75 \% \mathrm{GlcN}$ & $53.7^{\mathrm{a}}$ \\
\hline $1.5 \% \mathrm{GlcN}$ & $53.3^{\mathrm{ab}}$ \\
\hline $3.0 \% \mathrm{GlcN}$ & $52.5^{\mathrm{ab}}$ \\
\hline SEM & 0.38 \\
\hline$p$-value & 0.01 \\
\hline \multicolumn{2}{|c|}{ Storage time (days) } \\
\hline 0 & $54.0^{\mathrm{a}}$ \\
\hline 1 & $53.9^{\mathrm{a}}$ \\
\hline 2 & $53.8^{\mathrm{ab}}$ \\
\hline 3 & $52.4^{c}$ \\
\hline 4 & $52.2^{\mathrm{c}}$ \\
\hline 5 & $51.9^{\mathrm{c}}$ \\
\hline SEM & 0.40 \\
\hline p-value & $<0.01$ \\
\hline
\end{tabular}

${ }^{\mathrm{a}-\mathrm{f}}$ Means with different letter in the same column are significantly different at $p<0.01$. SEM - standard error of the mean. 
A

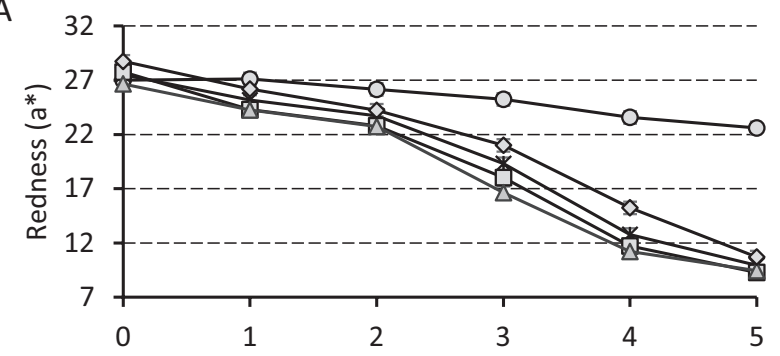

B

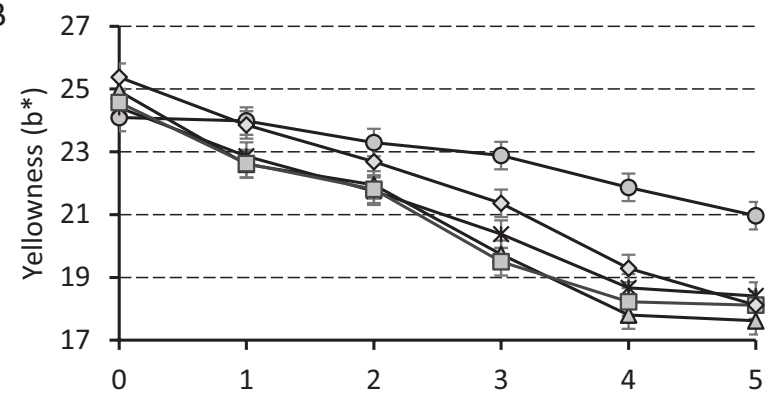

C

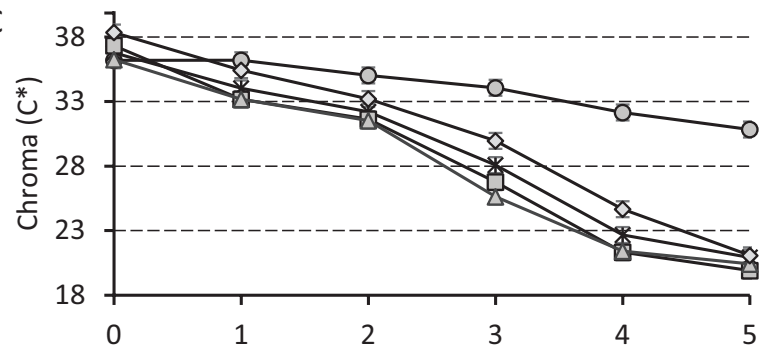

D

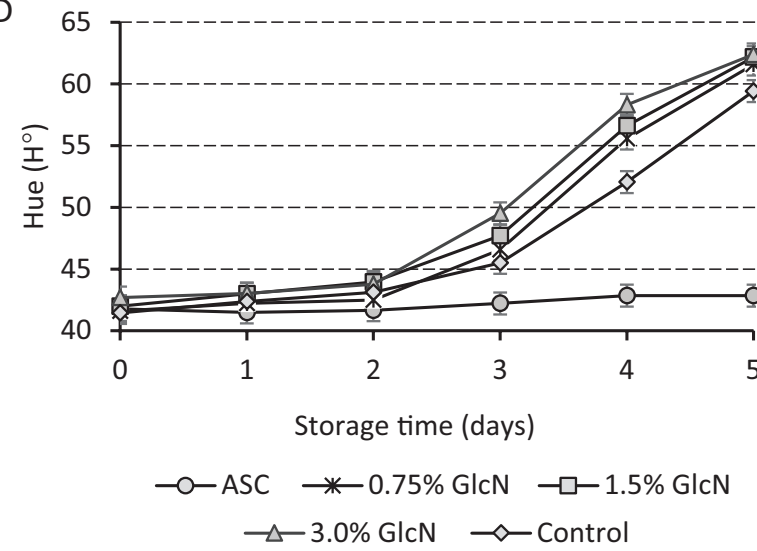

FIGURE 1. Instrumental colour measurements of beef burgers with glucosamine $(\mathrm{GlcN})$ and ascorbic acid (ASC) inclusion levels and time during refrigerated retail display for 5 days under aerobic packaging. A) redness; B) yellowness; C) chroma and D) hue angle. Values are expressed as means of three independent determinations \pm standard deviation.

\section{Cooking and textural characteristics of beef patties}

Of all the burger treatments, the highest cook loss was recorded in ASC samples followed by wheat crumb controls and those processed with $0.75 \%$ GlcN ( $p<0.05$, Table 3 ). Generally speaking, although other factors can also play a role, $\mathrm{pH}$ has been regarded as a crucial factor in the meat ability to hold water [Bendall \& Swatland, 1988]. This is because $\mathrm{pH}$ can influence both the net charge and the steric effects in meat system, the additive effect of which can impact meat water holding capacity (WHC). The low $\mathrm{pH}$ of raw ASC treatment (Table 4) can explain the high cook loss reported for this formulation (Table 3). The addition of ASC to the formulation led to more acidic environment which could bring the $\mathrm{pH}$ of meat protein close to its isoelectric point. This mechanism will result in reduced net charge on meat protein that could bind water molecules. The consequence is the reduced WHC and greater cook loss. Although antioxidants would be expected to limit oxidative changes and as such, improve water holding capacity and reduce cooking loss in meat system, the net charge effect due to reduced $\mathrm{pH}$ could have overpowered its subsequent protective effects. While the effect of ASC on cooking loss in beef has been scarcely reported, similar to the present study, Mitsumoto et al. [1995] have reported increased cooking loss in longissimus dorsi from cattle fed dietary vitamin E supplementation. A previous study by Mancini et al. [2015] however, found no significant difference in cooking loss between ASC and control treatments of rabbit burgers whereas, Peña et al. [2008] showed that increasing supplementation of ascorbic acid for broilers led to increasing cooking loss in broilers' breasts. It also seems consistent that, while antioxidant supplementation may improve drip loss and WHC in raw meat, this protective effect may be lost during subsequent meat cooking.

On the other hand, cooking losses were found to significantly decrease with increasing GlcN levels in burger formulations (Table 3). Thus, the more GlcN added, the less weight was lost during cooking. This could be explained by elevated ionic charges with increased addition of GlcN in burger system. Puolanne \& Halonen [2010] have previously reported that one amino acid of an ionic side chain could bind up to 4-7 water molecules. This higher concentration of ions will increase the solute concentration that may enhance water trapping in the burger system during cooking. Furthermore, the addition of GlcN to burger formulation appeared to enhance more protein extraction which may also support the elevated ionic charge with GlcN addition to the meat mixture. While this was not objectively quantified in this study, it was visually evident as GlcN led to increased stickiness of beef burger mixture during formulation and processing. Also, the increased GlcN in the meat system could have also resulted in elevated levels of hydroxyl hydrophilic groups which have the potential to attract more water molecules, further enhancing water retention during cooking. As observed, burgers with 1.5 and $3.0 \%$ GlcN also had significantly lower shrinkage for all dimensional parameters evaluated following cooking compared to all other treatment groups (Table 3). This signifies the potential of GlcN to enhance water holding capacity and increase yield in meat products on cooking.

The burgers formulated with GlcN were significantly $(p<0.05)$ softer as compared to controls processed with wheat crumb (Table 5). As previously explained and also evident with $\mathrm{pH}$ change with GlcN addition in cooked burger (Table 4), GlcN could have shifted the isoelectric point of protein in beef burger making more similar electric charges available to trap/immobilize water molecules. The repulsive energy created by these like charges may also create more structural spaces for water holding [Huff-Lonergan \& Lonergan, 2005]. 
TABLE 3. Cook loss and dimensional parameters for cooked beef burgers as affected by glucosamine (GlcN) and ascorbic acid (ASC) inclusion.

\begin{tabular}{|c|c|c|c|c|}
\hline Treatment & Cook loss $(\%)$ & Diameter change $(\%)$ & Thickness change (\%) & Total dimensional change (\%) \\
\hline Control & $30.2^{\mathrm{b}}$ & $16.7^{\mathrm{a}}$ & $12.1^{\mathrm{a}}$ & $14.3^{\mathrm{ab}}$ \\
\hline ASC & $33.3^{\mathrm{a}}$ & $16.6^{\mathrm{a}}$ & $14.6^{\mathrm{a}}$ & $15.6^{\mathrm{a}}$ \\
\hline $0.75 \% \mathrm{GlcN}$ & $29.7^{\mathrm{b}}$ & $16.4^{\mathrm{a}}$ & $12.9^{\mathrm{a}}$ & $14.6^{\mathrm{ab}}$ \\
\hline $1.5 \% \mathrm{GlcN}$ & $25.3^{\mathrm{c}}$ & $14.1^{\mathrm{b}}$ & $12.6^{\mathrm{a}}$ & $13.4^{\mathrm{b}}$ \\
\hline $3.0 \% \mathrm{GlcN}$ & $19.0^{\mathrm{d}}$ & $12.2^{\mathrm{c}}$ & $8.6^{\mathrm{b}}$ & $10.4^{c}$ \\
\hline SEM & 1.94 & 1.53 & 2.85 & 1.54 \\
\hline$p$-value & $<0.01$ & $<0.01$ & $<0.01$ & $<0.01$ \\
\hline
\end{tabular}

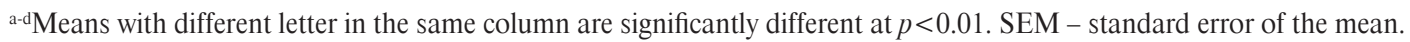

TABLE 4. $\mathrm{pH}$ values of raw and cooked burgers with glucosamine (GlcN) and ascorbic acid (ASC) inclusion.

\begin{tabular}{l|c|c}
\hline Treatment & Raw & Cooked \\
\hline Control & $5.70^{\mathrm{a}}$ & $5.88^{\mathrm{a}}$ \\
ASC & $5.54^{\mathrm{c}}$ & $5.73^{\mathrm{b}}$ \\
$0.75 \% \mathrm{GlcN}$ & $5.66^{\mathrm{b}}$ & $5.67^{\mathrm{b}}$ \\
$1.5 \% \mathrm{GlcN}$ & $5.65^{\mathrm{b}}$ & $5.54^{\mathrm{c}}$ \\
$3.0 \% \mathrm{GlcN}$ & $5.64^{\mathrm{b}}$ & $5.23^{\mathrm{d}}$ \\
SEM & 0.02 & 0.01 \\
$p$-value & $<0.01$ & $<0.01$ \\
\hline
\end{tabular}

${ }^{\mathrm{a}-\mathrm{d}}$ Means with different letter in the same column are significantly different at $p<0.01$. SEM - standard error of the mean.

The effect of these processes had both textural and water binding implication of the beef burger in this study resulting in softer product. Hardness values showed a decreasing trend as the GlcN incorporation level increased from 0.75 to $3.0 \%$. Chewiness results followed a similar pattern with control burgers being the chewiest and with gradual decrease in chewiness with increased addition of GlcN. Neither ASC nor $\mathrm{GlcN}$ affected $(p>0.05)$ cohesiveness or shear force of beef burgers, whereas the treatments containing ASC or
$0.75 \%$ GlcN had the lowest or highest $(p<0.05)$ springiness, respectively. Springiness however, tended to decrease with an increased incorporation of GlcN (Table 5). It is worth noting that, while cooking typically results in increased $\mathrm{pH}$ as observed for both ASC and control treatments (Table 4), addition of GlcN disrupted this trend. This disruption could be due to the degradation products of GlcN during heat treatment. Previous reports have also reported the reduction of $\mathrm{pH}$ values during GlcN thermal degradation [Hrynets et al., 2015; 2016; Dhungel et al., 2018]. This observation was claimed to be due to the formation of carboxylic and hydrocarboxylic acids during monosaccharide decomposition. Other studies have also reported the formation of acetic and formic acid due to the splitting of 1- and 3-deoxyglucosone, respectively [Brands \& van Boekel, 2001].

\section{Consumer acceptability of burgers}

The overall acceptability for burgers formulated with increasing levels of GlcN was only significantly affected at the $3.0 \%$ level GlcN (Figure 2). Similar result was observed for flavour, texture and aftertaste liking (results not shown). At this 3.0\% level of GlcN inclusion, consumers' liking for these attributes significantly decreased. Although other studies have reported tendency for improved flavour enhancement of food product with GlcN inclusion [Hong et al., 2016], similar observation was not evident for consumer flavour attributes liking of beef burger in this study. This could be due to the fact

TABLE 5. Textural properties for cooked burger as affected by glucosamine (GlcN) and ascorbic acid (ASC) addition.

\begin{tabular}{lcccccc}
\hline Treatment & Hardness $(\mathrm{N})$ & Cohesiveness & Springiness $(\mathrm{mm})$ & Chewiness $(\mathrm{N} \times$ mm $)$ & Shear force $(\mathrm{N})$ \\
\hline Control & $114.9^{\mathrm{a}}$ & 0.26 & $6.1^{\mathrm{b}}$ & $187.5^{\mathrm{a}}$ & 23.1 \\
ASC & $107.3^{\mathrm{ab}}$ & 0.28 & $5.8^{\mathrm{c}}$ & $172.4^{\mathrm{ab}}$ & 21.9 \\
$0.75 \% \mathrm{GlcN}$ & $100.5^{\mathrm{bc}}$ & 0.26 & $6.4^{\mathrm{a}}$ & $170.0^{\mathrm{ab}}$ & 21.5 \\
$1.5 \% \mathrm{GlcN}$ & $93.7^{\mathrm{cd}}$ & 0.28 & $6.2^{\mathrm{ab}}$ & $159.2^{\mathrm{b}}$ & 22.3 \\
$3.0 \% \mathrm{GlcN}$ & $86.8^{\mathrm{d}}$ & 0.27 & $6.1^{\mathrm{b}}$ & $145.5^{\mathrm{b}}$ & 23.9 \\
SEM & 8.72 & 0.02 & 0.17 & 16.76 & 2.23 \\
$p$-value & $<0.01$ & 0.08 & $<0.01$ & $<0.01$ & 0.28 \\
\hline
\end{tabular}

a-dMeans with different letter in the same column are significantly different at $p<0.01$. SEM - standard error of the mean. 
that all treatments had similar levels of seasoning mix minimizing the impact of GlcN. Furthermore, the flavour enhancing claims from GlcN have been largely attributed to its selfcondensation products; fructosazine and deoxyfructosazine as well as degradation products such as $\alpha$-dicarbonyls [Hrynets et al., 2016; Magaletta \& Ho, 1996; Tsuchida et al., 1990], and optimal conditions to enhance these reactions may not have been achieved in this study. Also, the impact may vary between different model food systems. A recent result from our laboratory has shown an increased consumer flavour liking score when glucosamine and glucosamine caramel (1\%) were added to breakfast sausage compared to control samples [Soladoye et al., 2021]. A recent study has also shown that glycation by GlcN can alter the taste profile of protein hydrolysates further highlighting the potential impact of GlcN on sensory attributes of food products [Fu et al., 2020].

Upon further exploration of the consumer acceptability rating of these burger formulations using the Check-AllThat--Apply procedure, it became evident that the decrease in consumer liking was the combination of deteriorating texture (as described in previous section) as well as flavour attributes. Figure $3 \mathrm{a}$ and Figure 3b, respectively, showed the flavour and texture variables that were selected by consumer to describe the different burger treatments. Employing a factor analysis for all the selected attributes, two factors that, respectively explained up to 95 and $89 \%$ of the variation in flavour and texture attributes in the burgers were computed. Factor 1 that explained up to $91 \%$ of flavour attributes adequately separated $3.0 \%$ GlcN from the other treatments and was largely associated with attributes such as bitter, tangy, off-flavour as well as some unacceptable sweetness level and fruity note (Figure 3a). Other burger treatments (especially the controls, ASC and $0.75 \% \mathrm{GlcN}$ ) formed a cluster with descriptors such as "good beef flavour", "tasty", "grilled flavour", and "spicy/seasoning". Attributes such as "metallic", "bland", "salty" and "livery" were not statistically significant based on consumer selection and as such did not impact the overall acceptability of any of the burger treatment. According to penalty analysis, up to

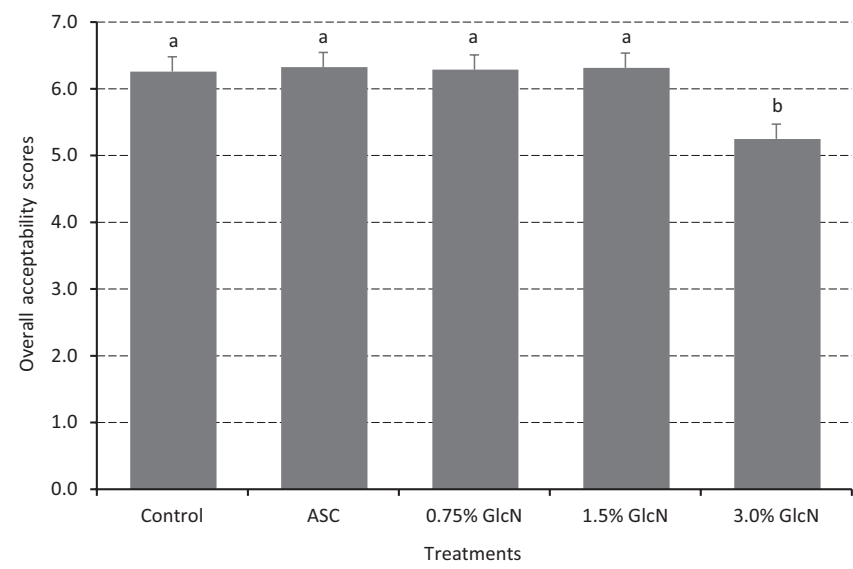

FIGURE 2. Mean consumer scores for overall acceptability of beef burger with varying levels of glucosamine $(\mathrm{GlcN})$ and (ascorbic acid) ASC inclusion; ${ }^{\mathrm{a} b \mathrm{~b}}$ Means with different letter on the same bar are significantly different at $p<0.001$.
$53 \%$ of the panelists were averse to the too sweet, too sour and low beef flavour of $3.0 \%$ GlcN burgers.

Texture descriptors associated with $3.0 \%$ GlcN include "greasy" and "rubbery" while the other treatments were largely described as "beefy", "crumbly" and "granular" texture (Figure 3b). Other textural attributes did not significantly affect consumer acceptability of the products. This was also evident in the penalty analysis where up 56 and $36 \%$ of the panelists, respectively adjudged the $3.0 \%$ GlcN burgers as too much fatty/oily mouth coating and too soft firmness, significantly decreasing the products' overall acceptability score (Table 6).

Similarly, on the Just-About-Right (JAR) scale, between 33 and $53 \%$ of the panelists described the saltiness, sweetness and sourness of $3.0 \% \mathrm{GlcN}$ as "too strong" while up to $54 \%$ of the panelists described the burger's beefy flavour as "too weak" (Table 7). On the other hand, between 50 and $73 \%$ of the consumer panelists described saltiness, sweetness and sourness of other treatments as JAR. While the overall beef flavour in the treatment has been penalized as being too weak, the beef flavour attribute of the $3.0 \% \mathrm{GlcN}$ has been described as JAR by the least number of consumers $(22 \%)$, with significantly higher penalty. It is important to note that, the magnitude of the penalty generally increases with an
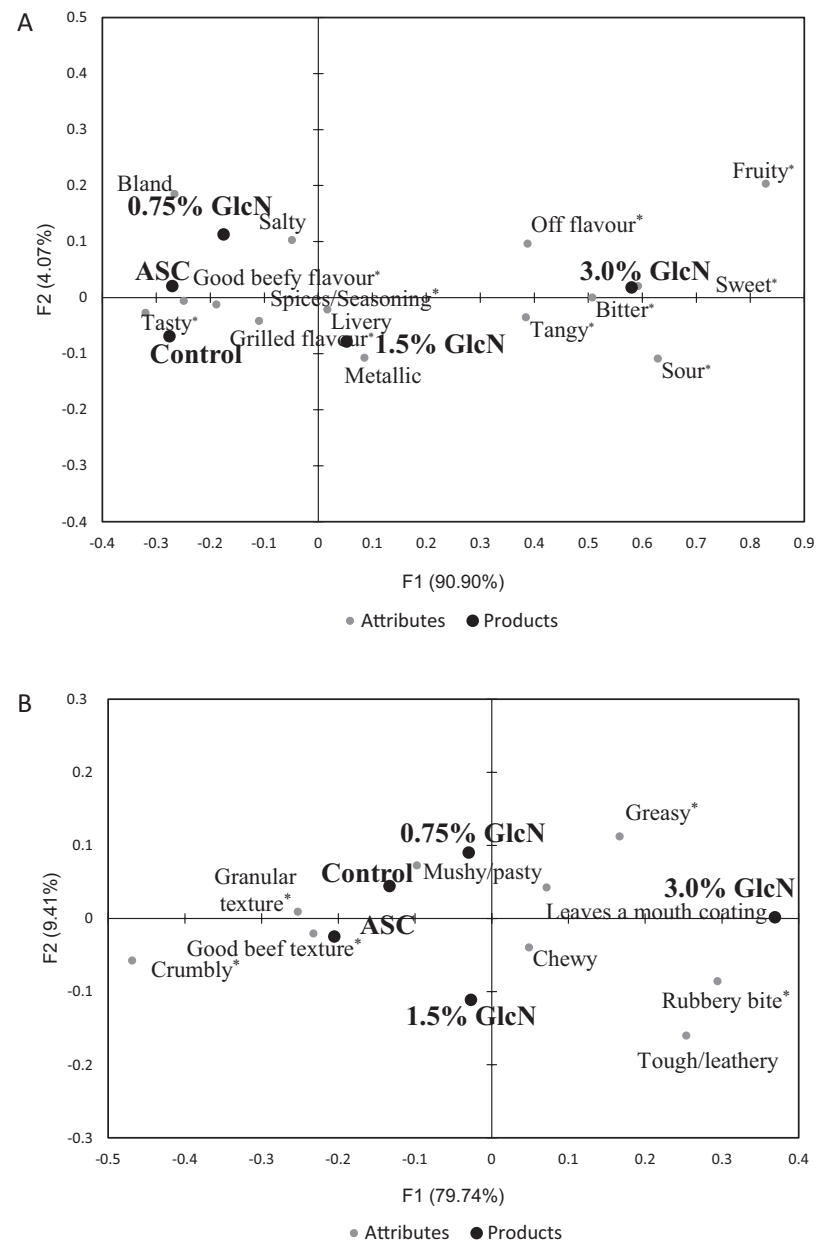

FIGURE 3. Check-All-That-Applies analyses for A) flavour and B) texture attributes defined by consumers as affected by glucosamine $(\mathrm{GlcN})$ and ascorbic acid (ASC) inclusion. Only attributes with asterisks were significant at $p<0.05$. 
TABLE 6. Penalty analysis and mean drop for texture attributes of beef burgers with glucosamine (GlcN) and ascorbic acid (ASC).

\begin{tabular}{|c|c|c|c|c|c|c|c|c|c|c|c|}
\hline & \multirow{2}{*}{ Levels } & \multicolumn{2}{|c|}{ Control } & \multicolumn{2}{|c|}{ ASC } & \multicolumn{2}{|c|}{$0.75 \% \mathrm{GlcN}$} & \multicolumn{2}{|c|}{$1.5 \% \mathrm{GlcN}$} & \multicolumn{2}{|c|}{$3.0 \% \mathrm{GlcN}$} \\
\hline & & $\begin{array}{c}\text { Selection } \\
\%^{1}\end{array}$ & $\begin{array}{c}\text { Mean } \\
\mathrm{OA}^{2}\end{array}$ & $\begin{array}{c}\text { Selection } \\
\%\end{array}$ & $\begin{array}{c}\text { Mean } \\
\text { OA }\end{array}$ & \begin{tabular}{|c|} 
Selection \\
$\%$
\end{tabular} & $\begin{array}{c}\text { Mean } \\
\text { OA }\end{array}$ & $\begin{array}{c}\text { Selection } \\
\%\end{array}$ & $\begin{array}{c}\text { Mean } \\
\text { OA }\end{array}$ & \begin{tabular}{|c|} 
Selection \\
$\%$
\end{tabular} & $\begin{array}{c}\text { Mean } \\
\text { OA }\end{array}$ \\
\hline \multirow{3}{*}{ Firmness } & Too soft & 23.2 & $4.4^{n+3+}$ & 27.8 & $4.6^{m+n}$ & 28.7 & $4.5^{m+1}$ & 15.7 & 4.5 & 36.1 & $3.9^{2 *+1}$ \\
\hline & JAR & 56.5 & 6.5 & 53.7 & 6.7 & 48.2 & 6.7 & 56.5 & 6.7 & 43.5 & 6.0 \\
\hline & Too firm & 20.4 & $5.1^{* *}$ & 18.5 & 5.4 & 23.2 & $5.4^{* *}$ & 27.8 & $5.5^{* *}$ & 20.4 & $4.4^{* *}$ \\
\hline \multirow[t]{2}{*}{ Overall penalty } & & \multicolumn{2}{|c|}{$1.785^{+4+5}$} & \multicolumn{2}{|c|}{$1.750^{*+*}$} & \multicolumn{2}{|c|}{$1.725^{+* a+}$} & \multicolumn{2}{|c|}{$1.567^{* \ldots}$} & \multicolumn{2}{|c|}{$1.913^{* n}$} \\
\hline & Too dry & 26.9 & $5.3^{*}$ & 21.3 & $5.3^{*}$ & 23.2 & 5.1 & 25.0 & $5.3^{*}$ & 13.0 & 4.5 \\
\hline \multirow[t]{2}{*}{ Juiciness } & JAR & 53.7 & 6.1 & 68.5 & 6.3 & 50.0 & 5.9 & 57.4 & 6.3 & 46.3 & 5.2 \\
\hline & Too juicy & 19.4 & 5.2 & 10.2 & 4.3 & 26.9 & 6.0 & 17.6 & 6.4 & 40.7 & 4.7 \\
\hline Overall penalty & & \multicolumn{2}{|c|}{$0.878^{*}$} & \multicolumn{2}{|c|}{$1.370^{* * *}$} & \multicolumn{2}{|c|}{0.333} & \multicolumn{2}{|c|}{0.551} & \multicolumn{2}{|c|}{1.285} \\
\hline \multirow{3}{*}{$\begin{array}{l}\text { Fatty/Oily mouth } \\
\text { coating }\end{array}$} & Too little & 9.3 & 5.1 & 15.7 & 5.1 & 16.7 & 5.6 & 14.8 & 5.1 & 7.4 & 4.1 \\
\hline & JAR & 48.2 & 6.1 & 51.9 & 6.4 & 38.0 & 6.1 & 50.9 & 6.5 & 37.0 & 5.5 \\
\hline & Too much & 42.6 & 5.4 & 32.4 & $5.5^{*}$ & 45.4 & 5.6 & 34.3 & 5.8 & 55.6 & $4.6^{\circ}$ \\
\hline Overall penalty & & \multicolumn{2}{|c|}{$0.740^{*}$} & \multicolumn{2}{|c|}{$0.992^{* * *}$} & \multicolumn{2}{|c|}{0.467} & \multicolumn{2}{|c|}{$0.924^{*}$} & \multicolumn{2}{|c|}{$0.956^{*}$} \\
\hline
\end{tabular}

${ }^{1}$ Selection \%: The percentage of consumers corresponding to the different collapsed Just-About-Right (JAR) levels; ${ }^{2}$ Mean OA; Mean overall acceptability corresponding to each JAR levels. " mean drop with level of significance $<0.001$, "mean drop with level of significance between 0.001 and 0.01 and "mean drop with level between significance $>0.01$ and $<0.05$.

TABLE 7. Penalty analysis and mean drop for flavour/taste attributes of beef burgers with glucosamine (GlcN) and ascorbic acid (ASC).

\begin{tabular}{|c|c|c|c|c|c|c|c|c|c|c|c|}
\hline & \multirow{2}{*}{ Levels } & \multicolumn{2}{|c|}{ Control } & \multicolumn{2}{|c|}{ ASC } & \multicolumn{2}{|c|}{$0.75 \% \mathrm{GlcN}$} & \multicolumn{2}{|c|}{$1.5 \% \mathrm{GlcN}$} & \multicolumn{2}{|c|}{$3.0 \% \mathrm{GlcN}$} \\
\hline & & $\begin{array}{c}\text { Selection } \\
\%^{1}\end{array}$ & $\begin{array}{c}\text { Mean } \\
\mathrm{OA}^{2} \\
\end{array}$ & \begin{tabular}{|c|} 
Selection \\
$\%$
\end{tabular} & $\begin{array}{c}\text { Mean } \\
\text { OA }\end{array}$ & $\begin{array}{c}\text { Selection } \\
\%\end{array}$ & $\begin{array}{c}\text { Mean } \\
\text { OA }\end{array}$ & \begin{tabular}{|c} 
Selection \\
$\%$
\end{tabular} & $\begin{array}{c}\text { Mean } \\
\text { OA }\end{array}$ & \begin{tabular}{|c|} 
Selection \\
$\%$
\end{tabular} & $\begin{array}{c}\text { Mean } \\
\text { OA }\end{array}$ \\
\hline \multirow{3}{*}{ Beef flavour } & Too strong & 35.2 & 6.6 & 45.4 & 6.7 & 41.7 & 6.6 & 36.1 & 6.7 & 24.1 & 6.3 \\
\hline & JAR & 38.9 & 7.0 & 31.5 & 6.7 & 31.5 & 6.7 & 39.8 & 6.9 & 22.2 & 7.1 \\
\hline & Too weak & 25.9 & $5.4^{n+* *+}$ & 23.2 & $5.1^{* *}$ & 26.9 & $5.3^{* *}$ & 24.1 & $4.9^{* * *+}$ & 53.7 & $3.8^{* * * *}$ \\
\hline \multirow[t]{2}{*}{ Overall penalty } & & \multicolumn{2}{|c|}{$0.870^{* * *}$} & \multicolumn{2}{|c|}{0.557} & \multicolumn{2}{|c|}{0.627} & \multicolumn{2}{|c|}{$0.907^{*}$} & \multicolumn{2}{|c|}{$2.542^{2 * n+4}$} \\
\hline & Too strong & 19.4 & 6.0 & 25.9 & $5.5^{* * * *}$ & 34.3 & $5.6^{* * * *}$ & 28.7 & $5.9^{*}$ & 33.3 & $4.3^{* *}$ \\
\hline \multirow[t]{2}{*}{ Saltiness } & JAR & 64.8 & 6.8 & 61.1 & 6.8 & 50.0 & 7.2 & 58.3 & 6.8 & 43.5 & 6.2 \\
\hline & Too weak & 15.7 & 5.7 & 13.0 & 5.8 & 15.7 & 5.1 & 13.0 & 4.9 & 25.1 & $4.3^{* *}$ \\
\hline \multirow[t]{2}{*}{ Overall penalty } & & \multicolumn{2}{|c|}{$0.929^{* *}$} & \multicolumn{2}{|c|}{$1.193^{*+n+4}$} & \multicolumn{2}{|c|}{$1.685^{+3+1}$} & \multicolumn{2}{|c|}{$1.263^{*+4}$} & \multicolumn{2}{|c|}{$1.923^{2+4+x}$} \\
\hline & Too strong & 10.2 & 5.8 & 11.1 & 5.0 & 19.4 & 5.6 & 28.7 & $5.7^{*}$ & 52.8 & $4.4^{* * * *}$ \\
\hline \multirow[t]{2}{*}{ Sweetness } & JAR & 68.5 & 6.7 & 63.9 & 6.6 & 57.4 & 6.8 & 50.0 & 6.7 & 33.3 & 6.7 \\
\hline & Too weak & 21.3 & $5.9^{*}$ & 25.0 & 6.2 & 23.2 & $5.6^{* *}$ & 21.3 & 6.3 & 13.9 & 4.4 \\
\hline \multirow[t]{2}{*}{ Overall penalty } & & \multicolumn{2}{|c|}{$0.820^{*}$} & \multicolumn{2}{|c|}{$0.828^{*}$} & \multicolumn{2}{|c|}{$1.214^{*+*}$} & \multicolumn{2}{|c|}{$0.741^{*}$} & \multicolumn{2}{|c|}{$2.319^{n+4 k}$} \\
\hline & Too strong & 11.1 & 5.4 & 11.1 & 4.8 & 17.6 & 5.4 & 30.6 & $5.1^{* * *}$ & 52.8 & $4.1^{13 *+}$ \\
\hline \multirow[t]{2}{*}{ Sourness } & JAR & 73.2 & 6.8 & 72.2 & 6.6 & 67.6 & 6.6 & 61.1 & 6.9 & 35.2 & 6.8 \\
\hline & Too weak & 15.7 & 5.7 & 16.7 & 6.1 & 14.8 & 5.9 & 8.3 & 6.7 & 12.0 & 4.9 \\
\hline Overall penalty & & \multicolumn{2}{|c|}{$1.220^{* *}$} & \multicolumn{2}{|c|}{$1.049^{* *}$} & \multicolumn{2}{|c|}{0.959} & \multicolumn{2}{|c|}{$1.489^{* *}$} & \multicolumn{2}{|c|}{$2.614^{* n+4}$} \\
\hline
\end{tabular}

${ }^{1}$ Selection \%: The percentage of consumers corresponding to the different collapsed Just-About-Right (JAR) levels; ${ }^{2}$ Mean OA; Mean overall acceptability corresponding to each JAR levels. " mean drop with level of significance $<0.001$, " mean drop with level of significance between 0.001 and 0.01 and ${ }^{*}$ mean drop with level between significance $>0.01$ and $<0.05$. 
increasing level of GlcN (Table 7). The firmness and juiciness of all other burger formulations except 3.0\% GlcN have been largely described by panelists (48-69\%) as JAR while between 41 and $56 \%$ of the panelists described $3.0 \%$ GlcN as too juicy and too much oily mouth coating. It therefore seems reasonable to conclude that excessive inclusion of glucosamine above $1.5 \%$ in burger formulation may be detrimental to the texture and greasy/oily attributes of the product as well as resulting in tangy, sour and off--flavoured burger, leading ultimately to consumer rejection of the product.

The impact of GlcN addition on the appearance liking of GlcN burgers was not significantly different from ASC and control treatment. Given that all the treatments were ranked between 6.0 and 6.6 on a 9-point hedonic scale, it generally seems that the appearance of burgers was more influenced by the variation inherent in the cooking process rather than the subjected treatments.

\section{CONCLUSION}

Aside from the health benefits of GlcN, which could qualify meat with GlcN as functional food, its moderate inclusion in various meat products formulation may also provide some technological advantages. GlcN may enhance meat products' water holding capacity and overall yield. While this may be beneficial to certain extent, inclusion above $1.5 \%$ may negatively affect consumer overall acceptability as a result of texture and flavour deterioration. In addition, GlcN may have impact on colour stability of meat products during refrigerated storage, however, this does not seem to affect consumer overall acceptability as this effect becomes irrelevant following cooking. Ascorbic acid preserved the colour attributes of beef burgers during refrigerated storage. It remains to be assessed if the colour change with GlcN will influence consumer first appeal of the raw/fresh products and hence, subsequent purchase. Given the novelty of this ingredient in meat application, other studies are still required to evaluate important technological impact of glucosamine in meat processing and quality.

\section{ACKNOWLEDGEMENTS}

Authors are grateful to the technical staff at the Food Processing Development Centre for their assistance.

\section{RESEARCH FUNDING}

The financial support by the Alberta Agriculture and Forestry's Strategic Research \& Development Program is greatly appreciated by the authors.

\section{CONFLICT OF INTEREST}

None to declare.

\section{ORCID IDs}

M. Betti https://orcid.org/0000-0002-4256-7174 P.O. Soladoye https://orcid.org/0000-0002-4446-2149

\section{REFERENCES}

1. Ahn, D.U., Nam, K.C. (2004). Effects of ascorbic acid and antioxidants on color, lipid oxidation and volatiles of irradiated ground beef. Radiation Physics and Chemistry, 71(1-2), 151-156. https://doi.org/10.1016/j.radphyschem.2004.04.012

2. Anderson, S. (2007). Determination of fat, moisture, and protein in meat and meat products by using the FOSS FoodScan near-infrared spectrophotometer with FOSS artificial neural network calibration model and associated database: collaborative study. Journal of AOAC International, 90(4), 1073-1083. https://doi.org/10.1093/jaoac/90.4.1073

3. Bendall, J.R., Swatland, H.J. (1988). A review of the realtionship of $\mathrm{pH}$ with physical aspects of pork quality. Meat Science, 24, 85-126.

https://doi.org/10.1016/0309-1740(88)90052-6

4. Bourne, M.C. (Ed.) (1982). Texture, viscosity and food. Food Texture and Viscosity, Academic Press, pp. 1-23. https://doi.org/10.1016/B978-0-12-119060-6.50006-X

5. Brands, C.M., van Boekel, M.A. (2001). Reactions of monosaccharides during heating of sugar-casein systems: Building of a reaction network model. Journal of Agricultural and Food Chemistry, 49(10), 4667-4675.

https://doi.org/10.1021/jf001430b

6. Bruyere, O., Reginster, J.Y. (2007). Glucosamine and chondroitin sulfate as therapeutic agents for knee and hip osteoarthritis. Drugs \& Aging, 24(7), 573-580.

https://doi.org/10.2165/00002512-200724070-00005

7. Chan, D.S.M., Lau, R., Aune, D., Vieira, R., Greenwood, D.C., Kampman, E., Norat, T. (2011). Red and processed meat and colorectal cancer incidence: meta-analysis of prospective studies. PloS One, 6(6), art. no. e20456.

https://doi.org/10.1371/journal.pone.0020456

8. Dhungel, P., Hrynets, Y., Betti, M. (2018). Sous-vide non-enzymatic browning of glucosamine at different temperatures. Journal of Agricultural and Food Chemistry, 66(17), 4521-4530.

https://doi.org/10.1021/acs.jafc.8b01265

9. Fu, Y., Liu, J., Zhang, W., Wæhrens, S.S., Tøstesen, M., Hansen, E.T., Bredie, W.L.P., Lametsch, R. (2020). Exopeptidase treatment combined with Maillard reaction modification of protein hydrolysates derived from porcine muscle and plasma: Structure-taste relationship. Food Chemistry, 306, art. no. 125613.

https://doi.org/10.1016/j.foodchem.2019.125613

10. Ganhão, R., Morcuende, D., Estévez, M. (2010). Protein oxidation in emulsified cooked burger patties with added fruit extracts: Influence on colour and texture deterioration during chill storage. Meat Science, 85(3), 402-409.

https://doi.org/10.1016/j.meatsci.2010.02.008

11. Gottardi, D., Hong, P.K., Ndagijimana, M., Betti, M. (2014). Conjugation of gluten hydrolysates with glucosamine at mild temperatures enhances antioxidant and antimicrobial properties. LWT - Food Science and Technology, 57(1), 181-187. https://doi.org/10.1016/j.Iwt.2014.01.013

12. Hong, P.K. (2016). Non-enzymatic browning in glucosamine and glucosamine-peptides reaction systems as a source of antioxidant and flavouring compounds. Doctoral Dissertation. University of Alberta, pp. 164 [https://era.library.ualberta.ca/ items/6fca2b48-4f56-4f39-9298-8e5f32618675]. 
13. Hong, P.K., Betti, M. (2016). Non-enzymatic browning reaction of glucosamine at mild conditions: Relationship between colour formation, radical scavenging activity and $\alpha$-dicarbonyl compounds production. Food Chemistry, 212, 234-243.

https://doi.org/10.1016/j.foodchem.2016.05.170

14. Hong, P.K., Ndagijimana, M., Betti, M. (2016). Glucosamine-induced glycation of hydrolysed meat proteins in the presence or absence of transglutaminase: Chemical modifications and taste-enhancing activity. Food Chemistry, 197, 1143-1152. https://doi.org/10.1016/j.foodchem.2015.11.096

15. Hrynets, Y., Bhattacherjee, A., Ndagijimana, M., Hincapie Martinez, D.J., Betti, M. (2016). Iron $\left(\mathrm{Fe}^{2+}\right)$-catalyzed glucosamine browning at $50^{\circ} \mathrm{C}$ : identification and quantification of major flavor compounds for antibacterial activity. Journal of Agricultural and Food Chemistry, 64(16), 3266-3275.

https://doi.org/10.1021/acs.jafc.6b00761

16. Hrynets, Y., Ndagijimana, M., Betti, M. (2015). Studies on the formation of Maillard and caramelization products from glucosamine incubated at $37^{\circ} \mathrm{C}$. Journal of Agricultural and Food Chemistry, 63, 6249-6261.

https://doi.org/10.1021/acs.jafc.5b02664

17. Hrynets, Y., Ndagijimana, M., Betti, M. (2013). Non-enzymatic glycation of natural actomyosin (NAM) with glucosamine in a liquid system at moderate temperatures. Food Chemistry, 139(1-4), 1062-1072.

https://doi.org/10.1016/j.foodchem.2013.02.026

18. Huff-Lonergan, E., Lonergan, S.M. (2005). Mechanisms of water-holding capacity of meat: The role of postmortem biochemical and structural changes. Meat Science, 71(1), 194-204.

https://doi.org/10.1016/j.meatsci.2005.04.022

19. Ismail, H.A., Lee, E.J., Ko, K., Paik, H.D., Ahn, D.U. (2009). Effect of antioxidant application methods on the color, lipid oxidation, and volatiles of irradiated ground beef. Journal of Food Science, 74(1), C25-C32.

https://doi.org/10.31274/ans_air-180814-1036

20. Jia, L., Wang, Y., Qiao, Y., Qi, Y., Hou, X. (2014). Efficient one-pot synthesis of deoxyfructosazine and fructosazine from D-glucosamine hydrochloride using a basic ionic liquid as a dual solvent-catalyst. RSC Advances, 4(83), 44253-44260.

https://doi.org/10.1039/C4RA06832G

21. Kralovec, J.A., Barrow, C.J. (2007). Glucosamine production and health benefits. In: C. Barrow, F. Shahidi (Eds.). Marine Nutraceuticals and Functional Foods, CRC Press, pp. 197-229. https://doi.org/10.1201/9781420015812.ch8

22. Magaletta, R.L., Ho, C.T. (1996). Effect of roasting time and temperature on the generation of nonvolatile (polyhydroxyalkyl) pyrazine compounds in peanuts, as determined by high-performance liquid chromatography. Journal of Agricultural and Food Chemistry, 44(9), 2629-2635.

https://doi.org/10.1021/jf960148v

23. Mancini, S., Preziuso, G., Dal Bosco, A., Roscini, V., Szendrő, Z., Fratini, F., Paci, G. (2015). Effect of turmeric powder (Curcuma longa L.) and ascorbic acid on physical characteristics and oxidative status of fresh and stored rabbit burgers. Meat Science, 110, 93-100.

https://doi.org/10.1016/j.meatsci.2015.07.005

24. McAlindon, T.E., LaValley, M.P., Gulin, J.P., Felson, D.T. (2000). Glucosamine and chondroitin for treatment of osteoarthri- tis: a systematic quality assessment and meta-analysis. JAMA, 283(11), 1469-1475.

https://doi.org/10.1001/jama.283.11.1469

25. Micha, R., Wallace, S.K., Mozaffarian, D. (2010). Red and processed meat consumption and risk of incident coronary heart disease, stroke, and diabetes mellitus: a systematic review and meta-analysis. Circulation, 121 (21), 2271-2283.

https://doi.org/10.1161/CIRCULATIONAHA.109.924977

26. Mitsumoto, M., Arnold, R.N., Schaefer, D.M., Cassens, R.G. (1995). Dietary vitamin E supplementation shifted weight loss from drip to cooking loss in fresh beef longissimus during display. Journal of Animal Science, 73(8), 2289-2294.

https://doi.org/10.2527/1995.7382289x

27. Mitsumoto, M., Cassens, R.G., Schaefer, D.M., Arnold, R.N., Scheller, K.K. (1991a). Improvement of color and lipid stability in beef longissimus with dietary vitamin E and vitamin C dip treatment. Journal of Food Science, 56(6), 1489-1492.

https://doi.org/10.1111/j.1365-2621.1991.tb08622.x

28. Mitsumoto, M., Faustman, C., Cassens, R.G., Arnold, R.N., Schaefer, D.M., Scheller, K.K. (1991b). Vitamins E and C improve pigment and lipid stability in ground beef. Journal of Food Science, 56(1), 194-197.

https://doi.org/10.1111/j.1365-2621.1991.tb08010.x

29. Peña, J.E.M., Vieira, S.L., López, J., Reis, R.N., Barros, R., Furtado, F.V.F., Silva, P.X. (2008). Ascorbic acid and citric flavonoids for broilers under heat stress: effects on performance and meat quality. Revista Brasileira de Ciência Avícola, 10(2), 125-130. https://doi.org/10.1590/S1516-635X2008000200008

30. Puolanne, E., Halonen, M. (2010). Theoretical aspects of water-holding in meat. Meat Science, 86(1), 151-165. https://doi.org/10.1016/j.meatsci.2010.04.038

31. Pietrasik, Z., Gaudette, N.J., Johnston, S.P. (2016a). The use of high pressure processing to enhance the quality and shelf life of reduced sodium naturally cured restructured cooked hams. Meat Science, 116, 102-109.

https://doi.org/10.1016/j.meatsci.2016.02.009

32. Pietrasik, Z., Gaudette, N.J., Klassen, M. (2016b). Effect of hot water treatment of beef trimmings on processing characteristics and eating quality of ground beef. Meat Science, 113, 41-50. https://doi.org/10.1016/j.meatsci.2015.11.011

33. Pietrasik, Z., Sigvaldson, M., Soladoye, O.P., Gaudette, N.J. (2020). Utilization of pea starch and fibre fractions for replacement of wheat crumb in beef burgers. Meat Science, 161, art. no. 107974.

https://doi.org/10.1016/j.meatsci.2019.107974.

34. Salvatore, S., Heuschkel, R., Tomlin, S., Davies, S.E., Edwards, S., Walker-Smith, J.A., French, I., Murch, S.H. (2000). A pilot study of $N$-acetyl glucosamine, a nutritional substrate for glycosaminoglycan synthesis, in paediatric chronic inflammatory bowel disease. Alimentary Pharmacology \& Therapeutics, 14(12), 1567-1579. https://doi.org/10.1046/j.1365-2036.2000.00883.x

35. Schaefer, D.M., Liu, Q., Faustman, C., Yin, M.C. (1995). Supranutritional administration of vitamins $\mathrm{E}$ and $\mathrm{C}$ improves oxidative stability of beef. The Journal of Nutrition, 125(suppl_6), 1792S-1798S.

https://doi.org/10.1093/jn/125.suppl_6.1792S

36. Sen, A.R., Muthukumar, M., Naveena, B.M., Ramanna, D.B.V. (2014). Effects on colour characteristics of buffalo meat dur- 
ing blooming, retail display and using vitamin $\mathrm{C}$ during refrigerated storage. Journal of Food Science and Technology, 51(11), 3515-3519.

https://doi.org/10.1007/s13197-012-0882-x

37. Shivas, S.D., Kropf, D.H., Hunt, M.C., Kastner, C.L., Kendall, J.L.A., Dayton, A.D. (1984). Effects of ascorbic acid on display life of ground beef. Journal of Food Protection, 47(1), 11-15.

https://doi.org/10.4315/0362-028X-47.1.11

38. Soladoye, O.P., Pietrasik, Z., Hrynets, Y., Betti, M. (2021). The effect of glucosamine and glucosamine caramel on quality and consumer acceptability of regular and reduced salt breakfast sausages. Meat Science, 172, art. no. 108310.

https://doi.org/10.1016/j.meatsci.2020.108310

39. Tsuchida, H., Komoto, M., Mizuno, S. (1990). Isolation and identification of polyhydroxyalkylpyrazines in soy sauce. Nippon Shokuhin Kogyo Gakkaishi, 37(2), 154-161.

https://doi.org/10.3136/nskkk1962.37.154
40. Uzzan, M., Nechrebeki, J., Labuza, T.P. (2007). Thermal and storage stability of nutraceuticals in a milk beverage dietary supplement. Journal of Food Science, 72(3), E109-E114. https://doi.org/10.1111/j.1750-3841.2007.00284.x

41. Uğraş, A., Güzel, E., Korkusuz, P., Kaya, İ., Dikici, F., Demirbaş, E., Çetinus, E. (2013). Glucosamine-sulfate on fracture healing. Ulus Travma Acil Cerrahi Derg, 19(1), 8-12. https://doi.org/10.5505/tjtes.2013.03256

42. Xing, R., Liu, S., Guo, Z., Yu, H., Li, C., Ji, X., Feng, J., Li, P. (2006). The antioxidant activity of glucosamine hydrochloride in vitro. Bioorganic \& Medicinal Chemistry, 14(6), 1706-1709. https://doi.org/10.1016/j.bmc.2005.10.018

43. Zhu, A., Huang, J.B., Clark, A., Romero, R., Petty, H.R. (2007). 2, 5-Deoxyfructosazine, a D-glucosamine derivative, inhibits T-cell interleukin-2 production better than D-glucosamine. Carbohydrate Research, 342(18), 2745-2749. https://doi.org/10.1016/j.carres.2007.08.025 
